Article

\title{
The Modification of a Tetrafunctional Epoxy and Its Curing Reaction
}

\author{
Mingming Yu *, Bin Feng ${ }^{\dagger}$, Wang Xie ${ }^{\dagger}$, Lin Fang ${ }^{\dagger}$, Hong Li ${ }^{\dagger}$, Liqi Liu ${ }^{\dagger}$, Musu Ren ${ }^{\dagger}$, \\ Jinliang Sun ${ }^{\dagger}$, Jiabao Zhang ${ }^{\dagger}$ and Hefeng $\mathrm{Hu}^{\dagger}$
}

Research Center for Composite Materials, Shanghai University, Shanghai 200072, China;

E-Mails: fengbing@shu.edu.cn (B.F.); wangxie@shu.edu.cn (W.X.); fanglin7@126.com (L.F.); lihong2007@shu.edu.cn (H.L.); 1lq@shu.edu.cn (L.L.); msren@shu.edu.cn (M.R.); jlsun@shu.edu.cn (J.S.); jbzhang@shu.edu.cn (J.Z.); huhefeng@shu.edu.cn (H.H.)

$\dagger$ These authors contributed equally to this work.

* Author to whom correspondence should be addressed; E-Mail: mmyu@shu.edu.cn; Tel.: +86-21-5633-2648; Fax: +86-21-5633-7502.

External Editor: Wen-Hsiang Hsieh

Received: 25 January 2015 / Accepted: 8 June 2015 / Published: 18 June 2015

\begin{abstract}
Recent experimental results showed that the $T_{\mathrm{g}}$ of cured resin scarcely decreased and the impact strength of resins increased by over $50 \%$ when a tetrafunctional epoxy named $N, N, N^{\prime}, N^{\prime}$-tetraglycidyl-4,4'-diaminodiphenyl ether (TGDDE) was introduced to an appropriate flexible chain from a dimer fatty acid (DFA). In order to understand the reason for this phenomenon, the modification and the chemical structure of the prepolymer together with the curing reaction and the viscoelasticity of the cured resins were studied in detail in the present work. The results indicated that the modification would help the prepolymer improve its molecular mobility. As a result, the resins could be further cured, resulting in the cross-linking density increasing. This is because the curing efficiency was increased, but the tetrafunctional epoxy was not cured completely due to its large steric hindrance. Moreover, the flexibility of some parts of the networks was improved, which was beneficial for the toughness of the cured resins. Therefore, the toughness of the tetrafunctional resin was improved with little influence on the thermal properties when the epoxies were modified with an appropriate content of DFA.
\end{abstract}

Keywords: modification; toughen; TGDDE; dimer fatty acid (DFA); curing reaction 


\section{Introduction}

As important thermosetting epoxy polymers, the amine based tetrafunctional epoxies were widely used as the matrices for fiber-composites materials [1-4]. Among these epoxies, $N, N, N^{\prime}, N^{\prime}$-tetraglycidyl-4,4'-diaminodiphenyl ether (TGDDE) was deemed the most commonly used one, because it had low viscosity, high reactivity and excellent thermal properties. However, the pure cured resins tend to be too brittle to be applied. Many methods were used to improve the toughness of the resin, including the modification on the molecular main chain by introducing a flexible chain, organic/inorganic hybridization, nanoparticle reinforcement, high temperature thermo-plastic blending toughening and aggregation state optimization [5-9]. Among these, the molecular chain modification with a flexible chain was an efficient way for improving the toughness of epoxy resins. However, it was nearly selected as a priority toughening method for the tetrafunctional epoxy resins, because this method was regarded to have a dispositive effect on the thermal property of the cured resin. However, the recent experiment results indicated that $T_{\mathrm{g}}$ of the cured resin scarcely decreased and the impact strength of the resins increased by over 50\% when TGDDE was modified with an appropriate dimer fatty acid (DFA) content [10], which verified that the tetrafunctional epoxy resin could be toughened by introducing a befitting flexible chain with the premise of little influence on the thermal properties. In order to understand the reason for this phenomenon, in the present work, TGDDE was modified with DFA as in Scheme 1. The modification was studied by Differential Scanning Calorimetry (DSC) method and Fourier Transform Infrared Spectroscopy (FTIR) dynamic method. Meanwhile, the chemical structure of the prepolymer was characterized by FTIR. After that, the epoxies were cured with methyl nadic anhydride (MNA) as Scheme 2 and Scheme 3, respectively. The curing behavior and curing kinetics of TGDDE/MNA and DFA-TGDDE/MNA systems were investigated by a non-isothermal DSC method. Moreover, the viscoelasticity of the cured resins was studied by the thermomechanical properties from dynamic mechanical analysis (DMA).
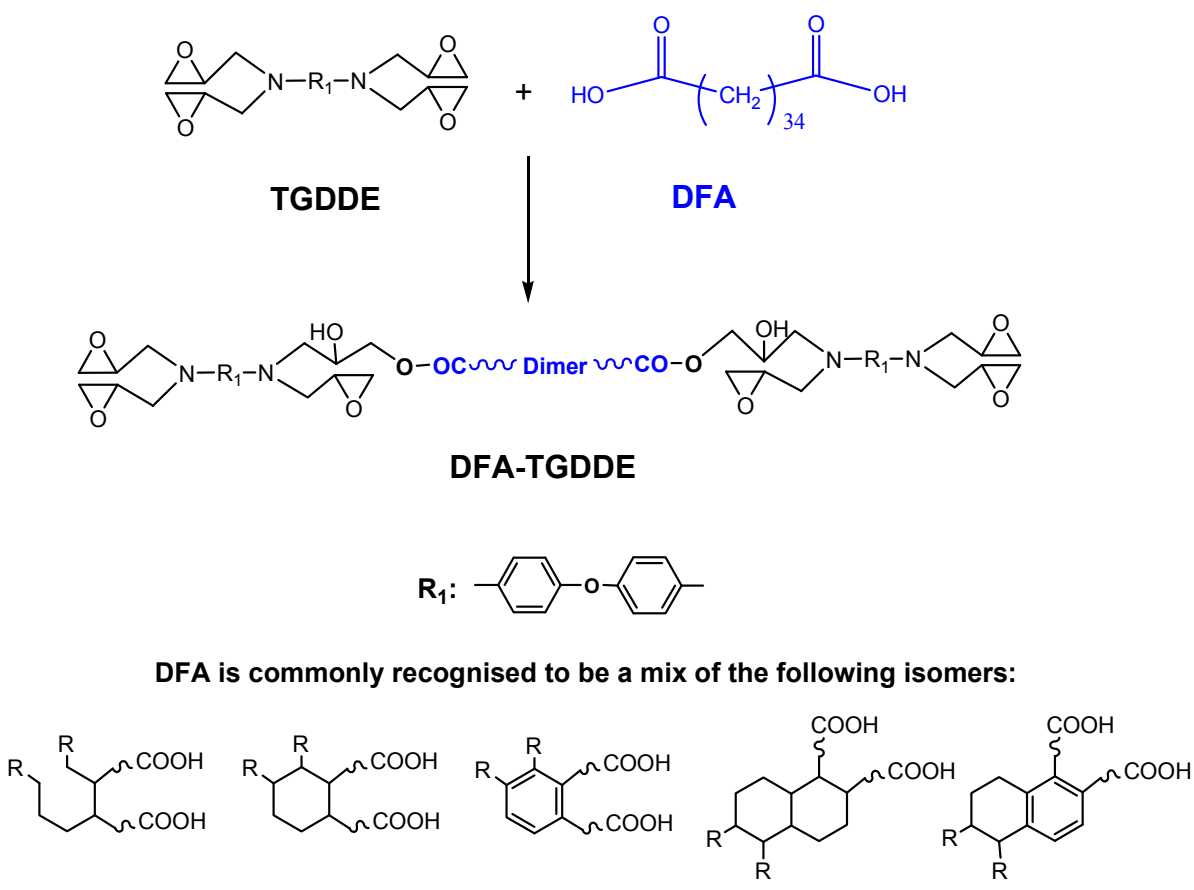

Scheme 1. The reaction between TGDDE and dimer fatty acid (DFA). 


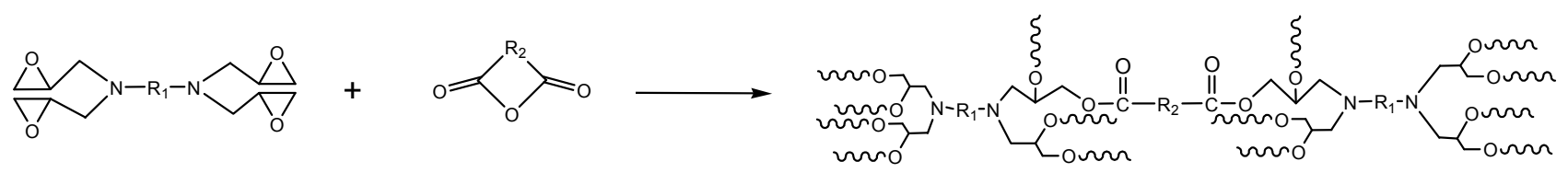

TGDDE

MNA
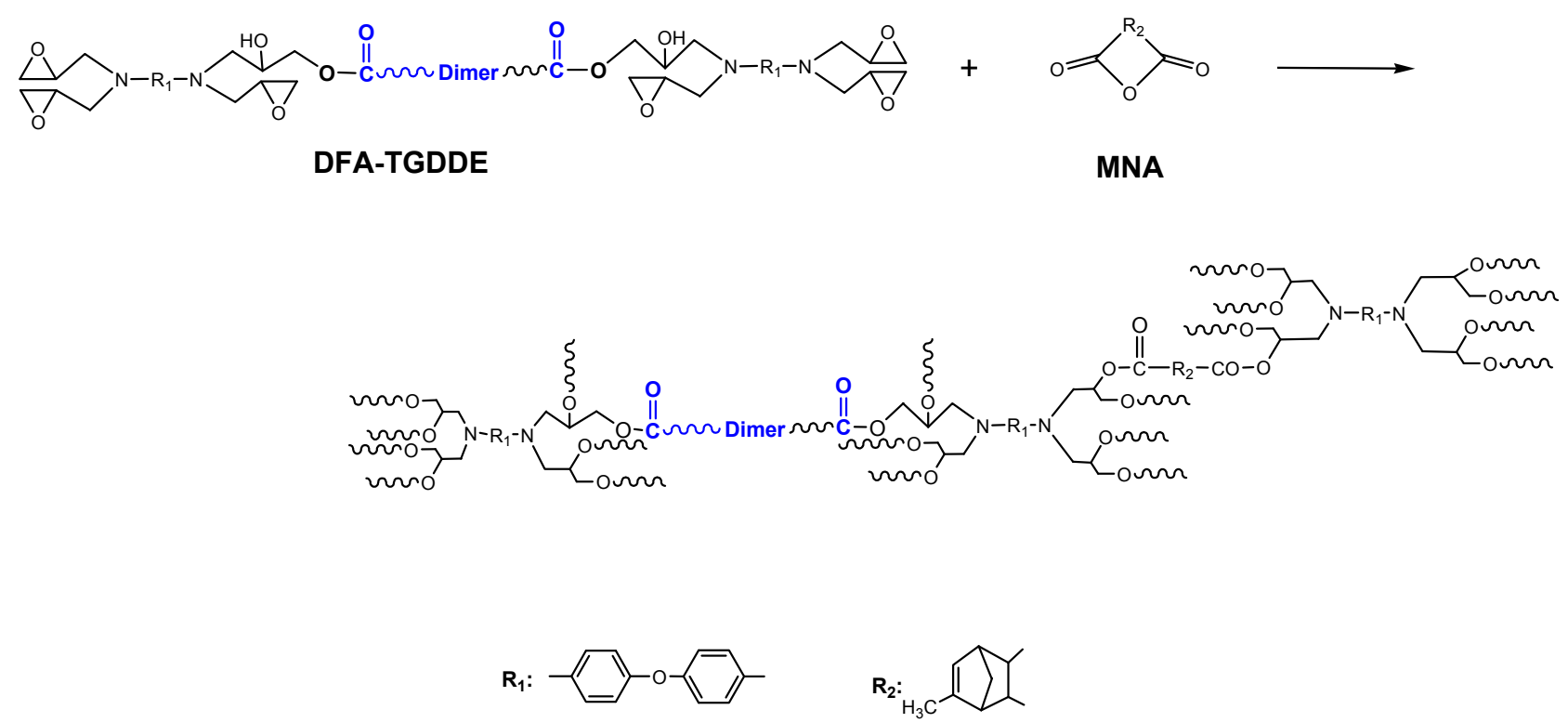

Scheme 2. The curing reaction of TGDDE/methyl nadic anhydride (MNA) and DFA-TGDDE/MNA systems.

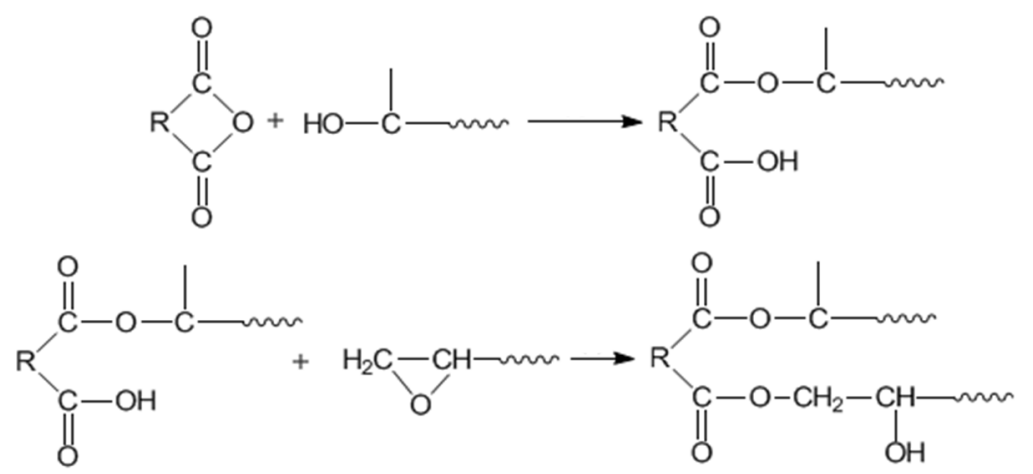

Scheme 3. The curing reaction between epoxy and anhydride (absence of catalyst).

\section{Results and Discussion}

\subsection{Modification of TGDDE with DFA}

The modification of TGDDE with DFA was through the reaction between the epoxy groups from TGDDE and the carboxyl groups from DFA, as Scheme 1 shows. The reaction process was characterized with the DSC method and the dynamic FTIR method.

The thermal behaviors of the reactions were studied by the DSC method, as shown in Figure 1. It can be seen that the exothermic reaction took place slowly and reached the maximum reaction rate at the peak temperature of $\sim 143{ }^{\circ} \mathrm{C}$ which increased slightly with the reaction proceeding, and then the reaction slowed down because less unreacted material was available. Moreover, the results revealed 
that the reaction enthalpy disappeared when the modification carried out under $100{ }^{\circ} \mathrm{C}$ for $40 \mathrm{~min}$, which illustrated that the reaction was accomplished at that condition.

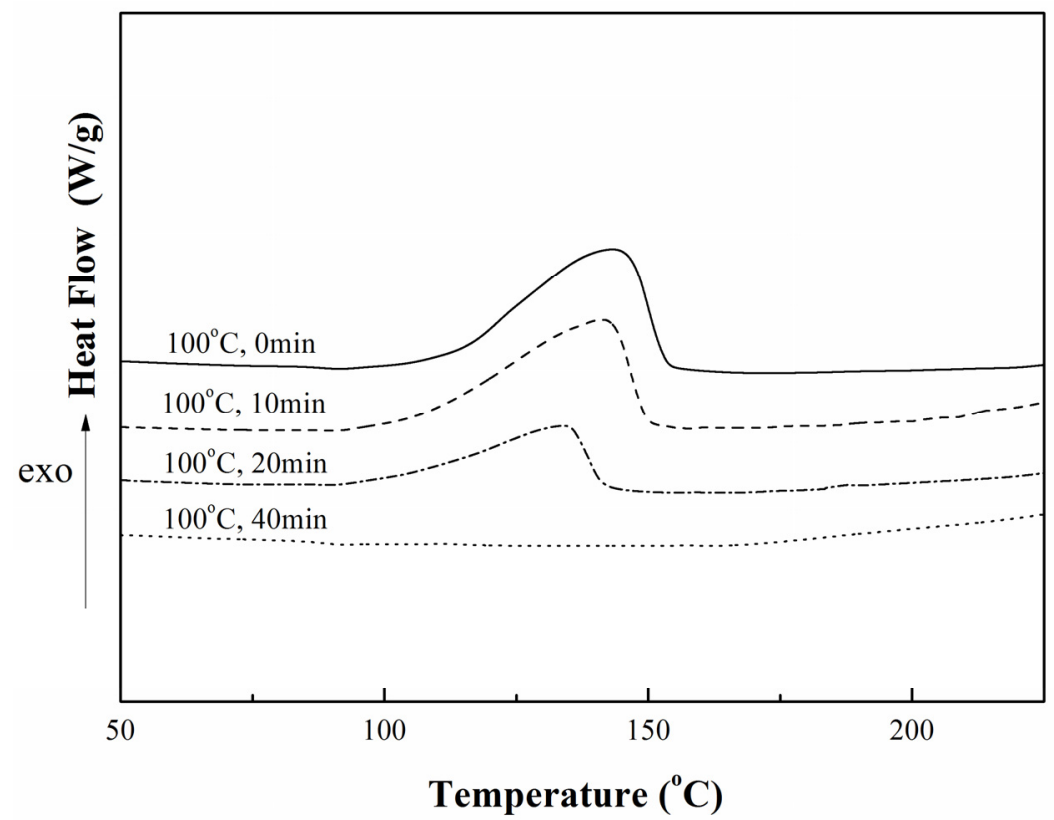

Figure 1. Differential Scanning Calorimetry (DSC) curves of 6\%DFA-TGDDE systems at various reaction times, $10^{\circ} \mathrm{C} / \mathrm{min}$.

In addition, as shown in Figure 2, the dynamic FTIR results indicated that the spectrum of carbonyl (1706-1733 $\mathrm{cm}^{-1}$ ) was shifted up with the reaction proceeding, which indicated that the ester group was being formed with the occurrence of the reaction between the carboxyl group and the epoxy group.

These results illustrated that the modification was accomplished under $100{ }^{\circ} \mathrm{C}$ for $40 \mathrm{~min}$, and the flexible chain from DFA was introduced into the molecular chain of the epoxy.

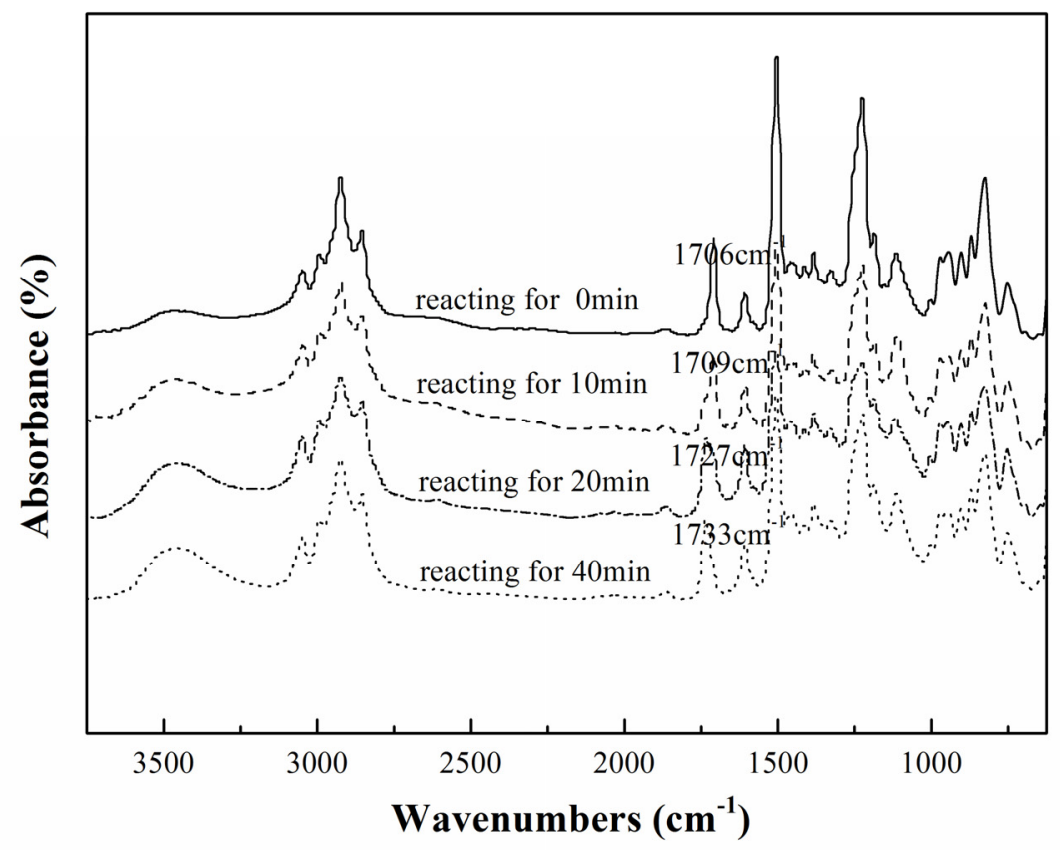

Figure 2. The chemical shifts of the modification process of $6 \%$ DFA-TGDDE systems. 
Furthermore, the chemical structure of the modified epoxy (DFA-TGDDE) was characterized by FTIR, as Figure 3 shown. The spectra were assigned as follows: $3452 \mathrm{~cm}^{-1}(\mathrm{O}-\mathrm{H}), 3045 \mathrm{~cm}^{-1}$, $2991 \mathrm{~cm}^{-1}, 2920 \mathrm{~cm}^{-1}$ and $2853 \mathrm{~cm}^{-1}(\mathrm{C}-\mathrm{H}), 1733 \mathrm{~cm}^{-1}(\mathrm{C}=\mathrm{O}), 1607 \mathrm{~cm}^{-1}$ and $1505 \mathrm{~cm}^{-1}$ (phenylene), $1230 \mathrm{~cm}^{-1}$ (Ar-O-Ar), $906 \mathrm{~cm}^{-1}\left(\overline{\mathrm{c}}_{\mathrm{o}^{-}}^{\mathrm{C}}\right)$.

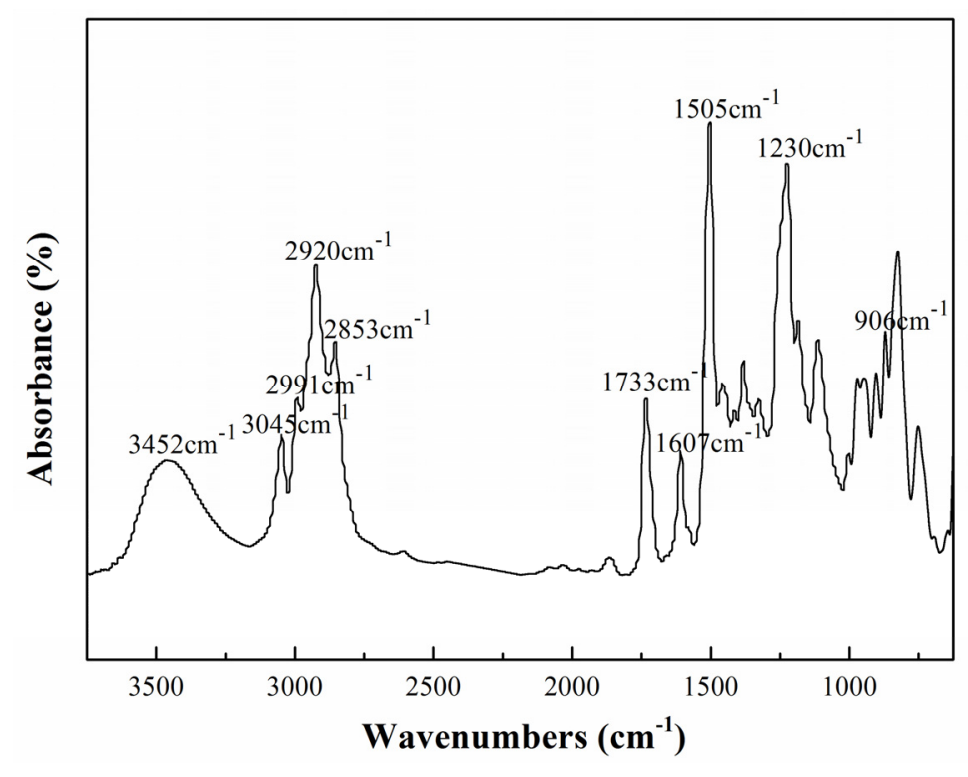

Figure 3. FTIR spectra of the 6\%DFA-TGDDE systems.

\subsection{Curing Reactions of TGDDE/MNA and DFA-TGDDE/MNA Systems}

In order to investigate the influence of the modification on the curing reactions, the curing behaviors and the curing kinetics of TGDDE/MNA and DFA-TGDDE/MNA were studied in detail.

\subsubsection{Curing Behaviors}

The curing behaviors of TGDDE/MNA and DFA-TGDDE/MNA systems were shown in Figure 4. The initial curing temperature $\left(T_{\mathrm{i}}\right)$, the peak curing temperature $\left(T_{\mathrm{p}}\right)$, the finishing temperature $\left(T_{\mathrm{f}}\right)$, and the curing reaction enthalpy $(\Delta H)$ of these curing reactions were summarized in Table 1 . Besides, the curing reaction between epoxy and anhydride occurred as in Scheme 3, which showed that the reaction occurred with two reactions and the reaction rate was controlled by the content of hydroxyl groups when the curing system was without catalyst. Therefore, the curing curve of TGDDE/MNA system showed bimodal character and the curves of DFA-TGDDE/MNA exhibited unimodal character, which were ascribed to the acceleration caused by the increasing content of hydroxyl groups. In addition, the results showed that the curing efficiency could be observably improved when the tetrafunctional epoxy modified with DFA since the initial curing temperature decreased with the increasing content of DFA. This phenomenon was also caused by the increasing content of hydroxyl groups. Additionally, the curing reaction enthalpy of all the systems pointed out that the curing system was further reacted after the modification. It is generally known that the multifunctional epoxy/anhydride systems were too difficult to be cured fully due to their large steric hindrance. However, the modification could improve the post curing reactions since the aliphatic chain of DFA would improve the mobility of the 
cross-linking networks in the latter curing reaction stage. Therefore, the curing systems were further cured when the epoxy was modified with DFA.

All the results indicated that the curing reactions could be improved when the tetrafunctional epoxy was modified with DFA.

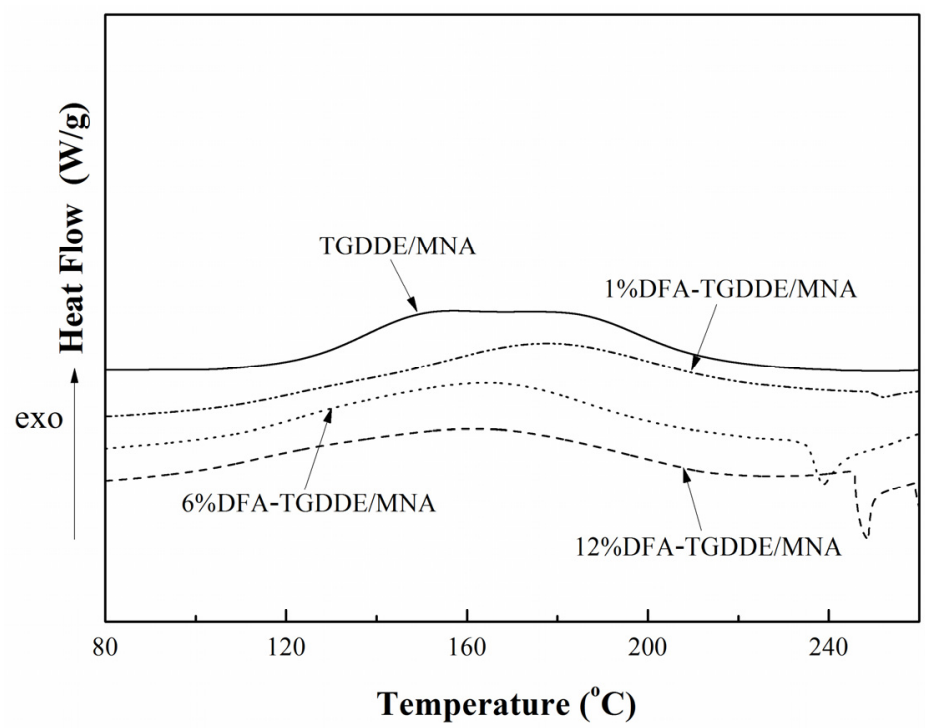

Figure 4. DSC curves of TGDDE and DFA-TGDDE curing with methyl nadic anhydride (MNA), $5^{\circ} \mathrm{C} / \mathrm{min}$.

Table 1. Characteristics of the curing systems, $5^{\circ} \mathrm{C} / \mathrm{min}$.

\begin{tabular}{ccccc}
\hline Systems & $\boldsymbol{T}_{\mathbf{i}}\left({ }^{\circ} \mathbf{C}\right)$ & $\boldsymbol{T}_{\mathbf{p}}\left({ }^{\circ} \mathbf{C}\right)$ & $\boldsymbol{T}_{\mathbf{f}}\left({ }^{\circ} \mathbf{C}\right)$ & $\boldsymbol{\Delta H}\left(\mathbf{J} \cdot \mathbf{g}^{-\mathbf{1}}\right)$ \\
\hline TGDDE/MNA & 122 & 187 & 216 & 109.5 \\
1\%DFA-TGDDE/MNA & 105 & 177 & 219 & 155.0 \\
6\%DFA-TGDDE/MNA & 98 & 165 & 213 & 189.3 \\
12\%DFA-TGDDE/MNA & 89 & 162 & 213 & 199.4 \\
\hline
\end{tabular}

\subsubsection{Curing Kinetics}

In order to further investigate the influence of the modification on the curing reactions, the reaction parameters of TGDDE/MNA and DFA-TGDDE/MNA systems were calculated from the curing kinetics with a non-isothermal DSC method [11], and the DSC curves of the curing reactions with different heating rates were shown in Figure 5. As a reactivity parameter, the apparent activation energies $\left(E_{a}\right)$ were calculated with the average values of the activation energy simulated by Kissinger's equation $\left(E_{k}\right)$ as Equation (1) [12] and the activation energy simulated by Ozawa's equation $\left(E_{o}\right)$ as in Equation (2) [13]. The results were listed in Table 2. It is shown that the curing efficiency increased after the modification since the apparent activation energies $\left(E_{a}\right)$ decreased with the increasing content of DFA:

$$
\begin{gathered}
\ln \left(\frac{\beta}{T_{p}^{2}}\right)=-\frac{E_{k}}{R} \frac{1}{T_{p}}+\ln \frac{A R}{E_{k}} \\
E_{o}=-\frac{R}{1.052} \frac{\mathrm{d} \ln \beta}{\mathrm{d}\left(1 / T_{p}\right)}
\end{gathered}
$$


where $E_{k}$ is the curing activation energy simulated by Kissinger's equation, $E_{o}$ is the curing activation energy simulated by Ozawa's equation. $\beta$ is the heating rate and $T_{p}$ is the maximum peak temperature, and $R$ is the ideal gas constant. The value of $E_{k}$ can be determined with a plot of $\ln \left(\beta / T_{p}^{2}\right) v s .1 / T_{p}$ as shown in Figure 6.

Additionally, as a steric hindrance parameter of the prepolymer, the pre-exponential factor $(A)$ was calculated as Equation (3), and the results were listed in Table 2. The results showed that the $A$ values sharply decreased after the modification, which illustrated that the modification would improve the flexibility of the molecular chain:

$$
A \approx \frac{\beta E \exp \left(E / R T_{p}\right)}{R T_{P}^{2}}
$$

Furthermore, the reaction rate constant $(k)$ was calculated from an Arrhenius equation (as Equation (4)). The $k$ values at different temperatures were shown in Figure 7. The value of $k$ was dependent on the temperature and increased with an increasing curing temperature. Moreover, when the curing temperature was below $160{ }^{\circ} \mathrm{C}(433 \mathrm{~K})$, the values of $k$ increased in the following order: TGDDE/MNA $<1 \%$ DFA-TGDDE/MNA $<6 \%$ DFA-TGDDE/MNA $<12 \%$ DFA-TGDDE/MNA. This revealed that the curing reaction rate was increased at the initial reaction stage when TGDDE was modified with DFA, and the influence would be much more remarkable with the increasing content of DFA:

$$
k=A \exp (-E / R T)
$$
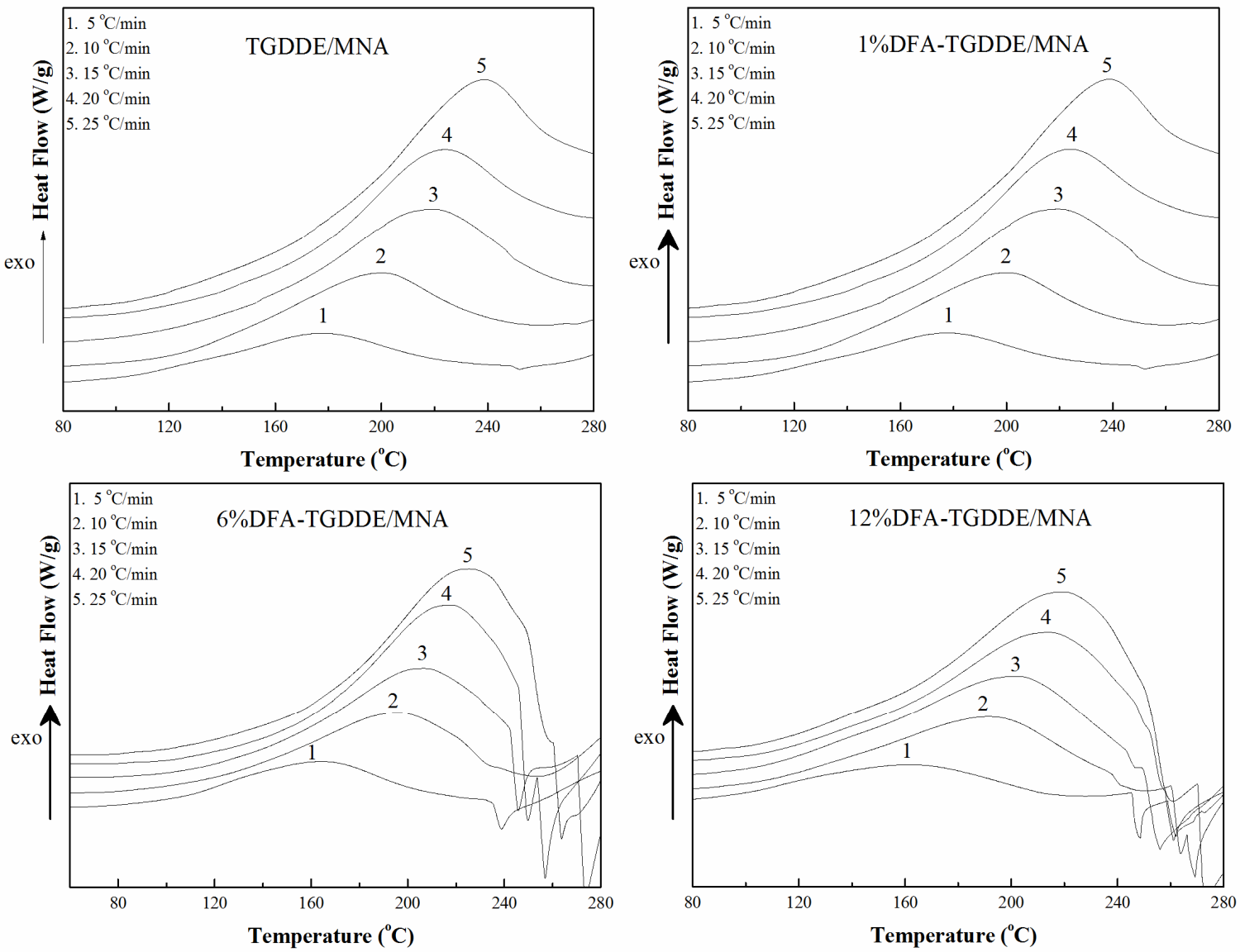

Figure 5. Enthalpy $v s$. Temperature of the curing process at different curing rate. 

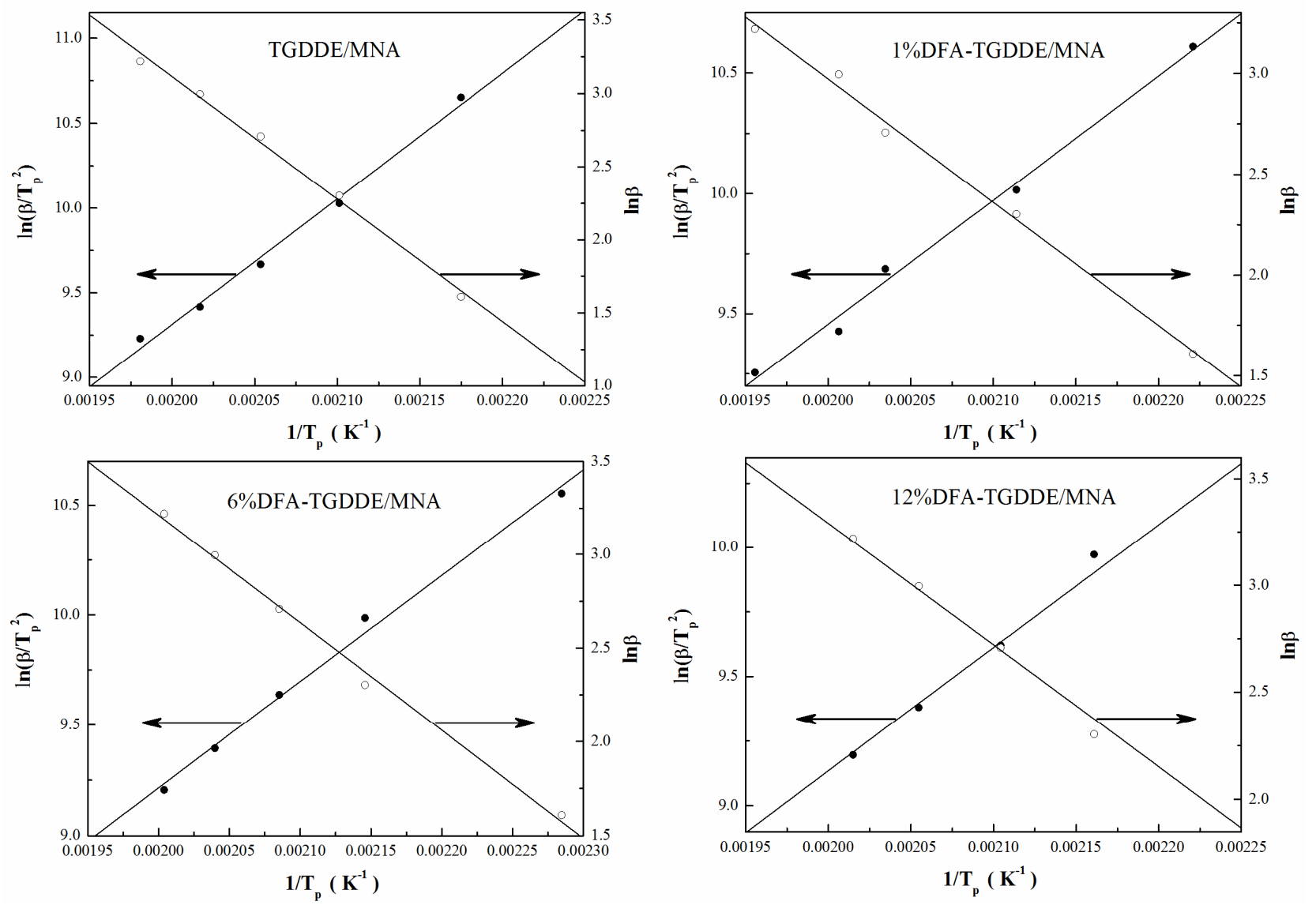

Figure 6. $\ln \left(\beta / T^{2}\right)$ and $\ln \beta$ vs. $1 / T_{\mathrm{p}}$ of the curing systems.

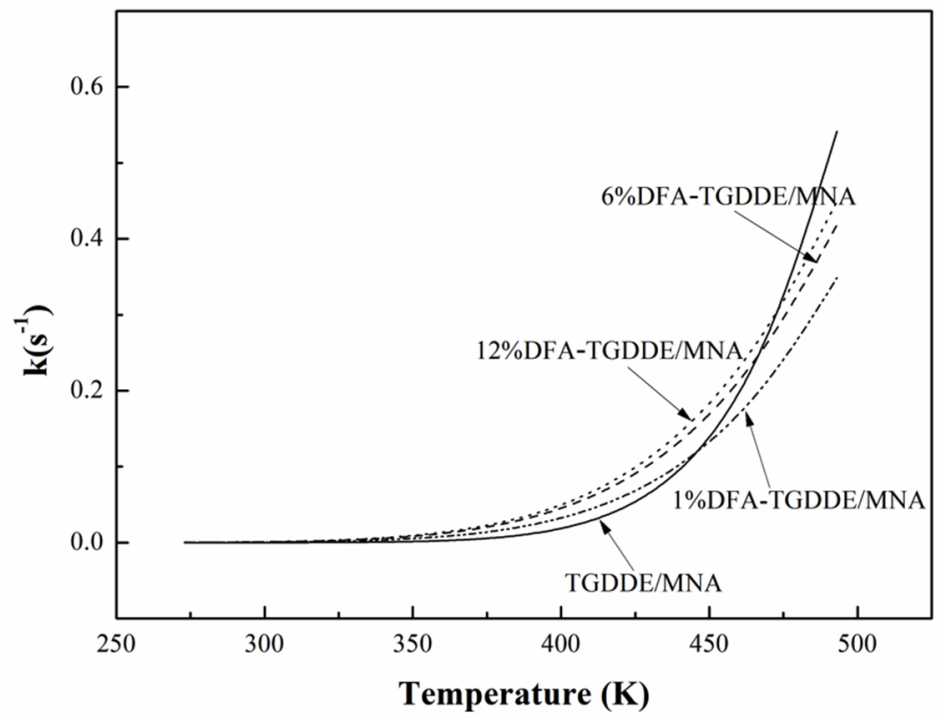

Figure 7. Curing reaction rate constant $(k)$ values at different temperatures.

In addition, the reaction order $n$ was obtained from the Crane's equation (as Equation (5)) [14], and the results were listed in Table 2. The calculated $n$ values of these curing reactions were all close to 0.9 , which illustrated that all these reactions could be approximately similar to the first order reaction:

$$
\frac{1}{n}=\frac{R}{E} \frac{\mathrm{d}(\ln \beta)}{\mathrm{d}\left(1 / T_{p}\right)}
$$


Table 2. The curing kinetic parameters of the curing systems.

\begin{tabular}{cccccc}
\hline Systems & $\boldsymbol{E}_{\boldsymbol{k}}(\mathbf{k J} / \mathbf{m o l})$ & $\boldsymbol{E}_{\boldsymbol{o}}(\mathbf{k J} / \mathbf{m o l})$ & $\boldsymbol{E}(\mathbf{k J} / \mathbf{m o l})$ & $\left.\boldsymbol{A} \mathbf{( s}^{-1}\right)$ & $\boldsymbol{n}$ \\
\hline TGDDE/MNA & 61.57 & 66.13 & 63.85 & $1.81 \times 10^{6}$ & 0.918 \\
1\%DFA-TGDDE/MNA & 42.88 & 48.32 & 45.60 & $1.22 \times 10^{4}$ & 0.897 \\
6\%DFA-TGDDE/MNA & 40.09 & 45.47 & 42.78 & $7.39 \times 10^{3}$ & 0.894 \\
12\%DFA-TGDDE/MNA & 39.65 & 45.01 & 42.33 & $7.14 \times 10^{3}$ & 0.894 \\
\hline
\end{tabular}

From the four calculated curing reaction parameters, it can be seen that the curing efficiency and the initial curing reaction rate would be increased on account of the decreasing activation energy and the more flexible molecular chain when TGDDE was modified with DFA. However, the reaction order $n$ was not affected after the modification, and all these reactions could be approximately similar to the first order reaction.

\subsection{Viscoelasticity of the Cured Resins}

The viscoelasticity of the cured resins was studied with their dynamic mechanical properties. As Figure 8 shows, the storage modulus of the cured resins decreased with increasing temperature due to the increasing flexibility of the molecular chain. Moreover, the modulus could be increased when the epoxy modified with an appropriate content DFA. Besides, the glass transition temperature $\left(T_{\mathrm{g}}\right)$ of the cured resin was calculated based on the rubber elasticity theory, and results were listed in Table 3. The results showed that the $T_{\mathrm{g}}$ of the cured resin was not obviously affected when the epoxy was modified with an appropriate content DFA. On the other hand, Figure 9 showed that the peak-intensities near the $T_{\mathrm{g}}$ of the loss modulus curves of DFA modified resin exhibited obvious reduction and the peak-width of them widened, which indicates that the stiffness of networks was relaxed because a flexible chain was introduced to the networks when the epoxy was modified with DFA. The effect was more obvious with increasing DFA content. In addition, the curves showed that the modified resins had obvious secondary relaxation at lower temperature, which was also caused by the mobility of a flexible chain of the networks. Additionally, Figure 10 showed $\tan \delta\left(\tan \delta=E^{\prime \prime} / E^{\prime}\right)$ curves of the cured resin, it illustrated that all the crosslinking networks were homogeneous systems since the curves exhibited one peak. Moreover, the curves indicated that the crosslinking density was related to the modifier, and it was not markedly affected when the epoxy was modified with an appropriate content DFA.

All the results illustrated that the toughness of the cured resins was improved after the modification, and the effect was more obvious with the DFA content. In addition, it can be seen that the $T_{\mathrm{g}}$ values and the cross-linking density of the cured resins were not remarkably affected when TGDDE was modified with an appropriate content DFA. However, the excess aliphatic chain would decrease the cross-linking density of the cured resins. 


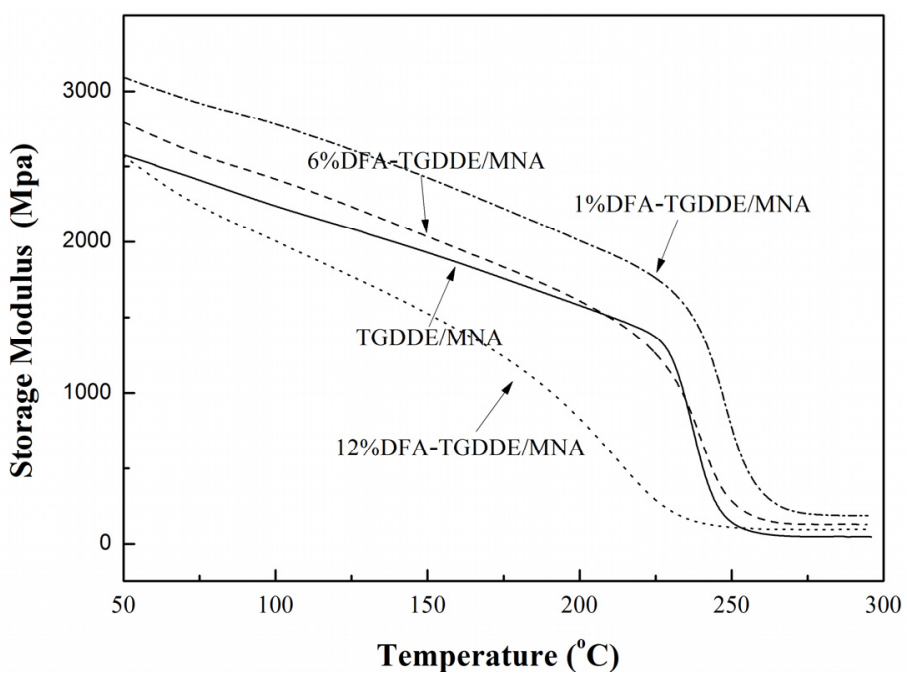

Figure 8. Storage modulus curves of the cured resins, $5^{\circ} \mathrm{C} / \mathrm{min}, 1 \mathrm{~Hz}$.

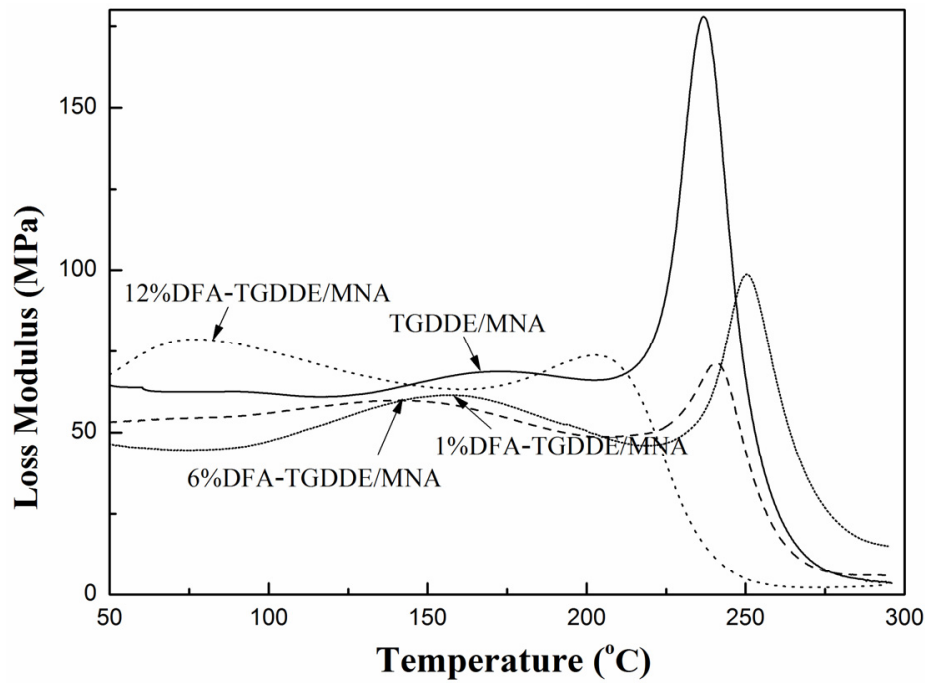

Figure 9. Loss modulus curves of the cured resins, $5^{\circ} \mathrm{C} / \mathrm{min}, 1 \mathrm{~Hz}$.

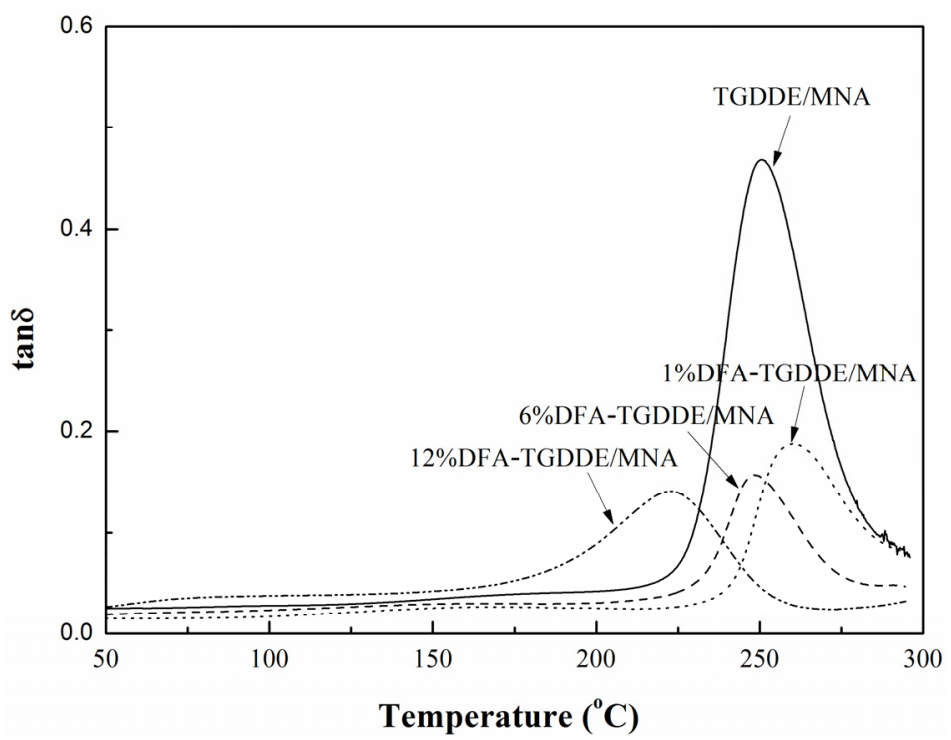

Figure 10. Tan $\delta$ curves of the cured resins, $5^{\circ} \mathrm{C} / \mathrm{min}, 1 \mathrm{~Hz}$. 
Table 3. The $T_{\mathrm{g}}$ and impact strength of the cured resins.

\begin{tabular}{ccccc}
\hline Systems & DFA $(\mathbf{g})$ & TGDDE $(\mathbf{g})$ & $\boldsymbol{T}_{\mathbf{g}}\left({ }^{\circ} \mathbf{C}\right)$ & Impact Strength $\left(\mathbf{k J} / \mathbf{m}^{2}\right)$ \\
\hline TGDDE/MNA & - & 100 & 230 & 4.14 \\
1\%DFA-TGDDE/MNA & 2 & 100 & 237 & 5.59 \\
6\%DFA-TGDDE/MNA & 14 & 100 & 228 & 6.31 \\
12\%DFA-TGDDE/MNA & 30 & 100 & 188 & 7.13 \\
\hline
\end{tabular}

\section{Experimental Section}

\subsection{Materials}

Methyl nadic anhydride (MNA) was purchased from Aldrich (St. Louis, MO, USA). Dimer acid (DFA, PRIPOL 1013) with acid value $195 \mathrm{mg} / \mathrm{KOH}$ was obtained from Croda (Cowick Hall, UK). $N, N, N^{\prime}, N^{\prime}$-tetraglycidyl-4,4'-diaminodiphenyl ether (TGDDE) with epoxy equivalent weight (EEW) $120 \mathrm{~g} / \mathrm{mol}$ was supplied by department of polymer materials of Shanghai University. All chemical agents were used without further purification.

\subsection{Preparation of $D F A-T G D D E$}

In order to investigate the modification between TGDDE and DFA, these two compounds were mixed at room temperature, and then reacted at $100{ }^{\circ} \mathrm{C}$ for several minutes. Thus, four samples were prepared, which were the system of TGDDE mixing with DFA at room temperature (assuming unreacted, named reacting for $0 \mathrm{~min}$ ), the system of TGDDE reacting with DFA for $10 \mathrm{~min}$ at $100{ }^{\circ} \mathrm{C}$ (named reacting for $10 \mathrm{~min}$ ), the system of TGDDE reacting with DFA for $20 \mathrm{~min}$ at $100{ }^{\circ} \mathrm{C}$ (named reacting for $20 \mathrm{~min}$ ) and the system of TGDDE reacting with DFA for $40 \mathrm{~min}$ at $100{ }^{\circ} \mathrm{C}$ (named reacting for $40 \mathrm{~min}$ ).

Additionally, DFA-TGDDE was prepared as the formula showed in Table 4, and the mixture was reacted in a three necked flask with stirring at $100{ }^{\circ} \mathrm{C}$ for $40 \mathrm{~min}$.

Table 4. The formula of DFA-TGDDE and their epoxy equivalent weight (EEW).

\begin{tabular}{cccc}
\hline Systems & DFA $(\mathbf{g})$ & TGDDE $(\mathbf{g})$ & EEW $(\mathbf{g} / \mathbf{m o l})$ \\
\hline 1\%DFA-TGDDE & 2 & 100 & 121 \\
6\%DFA-TGDDE & 14 & 100 & 128 \\
12\%DFA-TGDDE & 30 & 100 & 137 \\
\hline
\end{tabular}

\subsection{Preparation of Cured Epoxy Resins}

The modified epoxy was mixed with a stoichiometric amount of the curing agent (MNA) as Table 5 shown, and then the mixture was heated to $65{ }^{\circ} \mathrm{C}$ under vacuum to remove air bubbles and moisture. Subsequently, the mixture was cured at $100{ }^{\circ} \mathrm{C}$ for $2 \mathrm{~h}$, followed by curing at $160{ }^{\circ} \mathrm{C}$ for $2 \mathrm{~h}$, and finally post cured at $200^{\circ} \mathrm{C}$ for $4 \mathrm{~h}$. 
Table 5. The formula of TGDDE/MNA and DFA-TGDDE/MNA systems.

\begin{tabular}{ccc}
\hline Systems & Epoxy $(\mathbf{g})$ & Curing Agent $(\mathbf{g})$ \\
\hline TGDDE/MNA & 100 & 126 \\
1\%DFA-TGDDE/MNA & 100 & 125 \\
6\%DFA-TGDDE/MNA & 100 & 118 \\
12\%DFA-TGDDE/MNA & 100 & 110 \\
\hline
\end{tabular}

\subsection{Characterization}

FTIR spectrum was recorded on a Nicolet 380 infrared spectrometer (Waltham, MA, USA) in the range of $4000-400 \mathrm{~cm}^{-1}$, and the sample was spread on the $\mathrm{KBr}$ slice.

Differential Scanning Calorimetry (DSC) was performed on a TA Q2000 (New Castle, MO, USA) with a constant nitrogen flow of $50 \mathrm{~mL} / \mathrm{min}$. About $5 \mathrm{mg}$ of a sample (DFA-TGDDE, TGDDE/MNA, DFA-TGDDE/MNA) was weighted and put into a hermetic aluminum sample pan at $25{ }^{\circ} \mathrm{C}$, which was then sealed, and the sample was tested immediately. The dynamic scanning experiment ranged from 80 to $270{ }^{\circ} \mathrm{C}$. The curing behaviors and the curing kinetics were studied with a non-isothermal DSC method.

Dynamic mechanical analysis (DMA) was characterized with a TA Q800 in the air. The specimen of $60 \mathrm{~mm} \times 10 \mathrm{~mm} \times 3 \mathrm{~mm}$ was loaded in a three-point bending mode from 50 to $300{ }^{\circ} \mathrm{C}$ at a heating rate of $5{ }^{\circ} \mathrm{C} / \mathrm{min}$ with a frequency of $1 \mathrm{~Hz}$.

\section{Conclusions}

A tetrafunctional epoxy named TGDDE was modified with DFA, and the prepolymer was cured with MNA. The modification and curing reaction together with the viscoelasticity of the cured resins were studied in detail. The results from the modification verified that the flexible chain from DFA was introduced into the molecular chain of the epoxies when TGDDE reacted with DFA under $100{ }^{\circ} \mathrm{C}$ for $40 \mathrm{~min}$. Moreover, the curing reaction parameters revealed that the prepolymer could be further cured when TGDDE was modified with DFA. This is because that the curing efficiency was improved on account of the decreasing activation energy and the improving molecular chain mobility, while the tetrafunctional epoxy was hardly cured completely duo to its large steric hindrance. Thus, the cross-linking density of the networks was not remarkably influenced when TGDDE was modified with an appropriate content of DFA, although the long flexible chain would decrease the cross-linking density. On the other hand, the viscoelasticity of the cured resins illustrated that the modification would improve the mobility of the networks, which was beneficial for the toughness of the cured resin. Therefore, the toughness of the tetrafunctional resin was improved with little influence on the thermal properties when the epoxies were modified with an appropriate content of DFA.

\section{Acknowledgments}

This work was supported by the foundation of Hubei Provincial Engineering Laboratory for Resin Matrix Structural and Functional Composite Materials (No.JX0100.0172). 


\section{Author Contributions}

Mingming $\mathrm{Yu}$, Lin Fang and Wang Xie conceived and designed the experiments; Bin Feng, Hong Li and Liqi Liu performed the experiments; Musu Ren, Jiabao Zhang and Jinliang Sun analyzed the data; Hefeng Hu contributed reagents and analysis tools; Mingming Yu wrote the paper.

\section{Conflicts of Interest}

The authors declare no conflict of interest.

\section{References}

1. Chen, X.B. Handbook of Composites Based on Polymer; Chemical Industry Press: Beijing, China, 2004.

2. Toldy, A.; Szolnoki, B.; Marosi, G. Flame retardancy of fibre-reinforced epoxy resin composites for aerospace applications. Polym. Degrad. Stab. 2011, 96, 371-376.

3. Edwards, E.R.; Kostov, K.G.; Botelho, E.C. Evaluation of the chemical interaction between carbon nanotubes functionalized with TGDDM tetrafunctional resin and hardener DDS. Compos. B Eng. 2013, 51, 197-203

4. Chen, W.M.; Tao, Z.Q.; Fan, L.; Yang, S.Y.; Jiang, W.G.; Wang, J.F.; Xiong, Y.L. Effect of poly(etherimide) chemical structures on the properties of epoxy/poly(etherimide) blends and their carbon fiber-reinforced composites. J. Appl. Polym. Sci. 2011, 119, 3162-3169.

5. Charalampos, K.; Everson, K.; Baljinder, K.K. The effect of nanoparticles on structural morphology, thermal and flammability properties of two epoxy resins with different functionalities. Polym. Degrad. Stab. 2011, 96, 529-540.

6. Kinloch, A.J.; Lee, S.H.; Taylor, A.C. Improving the fracture toughness and the cyclic-fatigue resistance of epoxy-polymer blends. Polymer 2014, 55, 6325-6334.

7. Zhang, J.; Niu, H.T.; Zhou, J.G.; Wang, H.G.; Lin, T. Synergistic effects of PEK-C/VGCNF composite nanofibres on a trifunctional epoxy resin. Compos. Sci. Technol. 2011, 71, 1060-1067.

8. Li, G.; Huang, Z.B.; Xin, C.L.; Jia, X.L.; Yang, X.P. Curing kinetics and mechanisms of polysulfone nanofibrous membranes toughened epoxy/amine systems using isothermal DSC and NIR. Thermochim. Acta 2010, 497, 27-34.

9. Wang, Y.S. Solvent Resistance of Epoxy Resins Toughened with Polyethersulfone. US8686069 B2, 12 October 2010.

10. Yu, M.M.; Feng, B.; Yang, M.; Liu, L.Q.; Li, H.; Ren, M.S.; Sun, J.L.; Zhang, J.B. Toughness and thermal properties of a dimer acid modified tetrafunctional epoxy resin. Appl. Mech. Mater. 2015, 764, 107-110.

11. Dai, Z.; Li, Y.F.; Yang, S.G.; Zhao, N.; Zhang, X.L.; Xu, J. Kinetics and thermal properties of epoxy resins based on bisphenol fluorine. Eur. Polym. J. 2009, 45, 1941-1948.

12. Kissinger, H.E. Reaction kinetics in differential thermal analysis. Anal. Chem. 1957, 29, 1702-1706. 
13. Ozawa, T. A new method of analyzing thermogravimetric data. Bull. Chem. Soc. Jpn. 1965, 38, $1881-1886$.

14. Crane, L.W.; Dynes, P.J.; Kaelble, D.H. Analysis of curing kinetics in polymer composites. J. Polym. Sci. Polym. Lett. Ed. 1973, 11, 533-540.

(C) 2015 by the authors; licensee MDPI, Basel, Switzerland. This article is an open access article distributed under the terms and conditions of the Creative Commons Attribution license (http://creativecommons.org/licenses/by/4.0/). 